\title{
Reptes organitzatius de l'Escola Valenciana del futur CEIP Manel Garcia Grau
}


La vessant didàctica de l'Educació és summament important -de fet, hauria de ser l'objectiu principal de l'Educació. Des de l'estudi inicial de la teoria educativa dels autors, passant per aspectes com l'atenció a la diversitat, els aspectes psicopedagògics de l'alumnat i l'entrenament didàctic en cadascuna de les àrees de coneixement, he anat desenvolupant una anàlisi interior de les claus essencials per definir la meua tasca educativa de cara al futur. He trobat respostes a interrogants que, sens dubte, tot docent ha d'assolir: què és educar?; quina és l'essència de l'Educació?; quina és la seua base teoricopràctica?; quins són els objectius de l'acte educatiu?; què és el que s'ensenya o s'haguera d'ensenyar?; amb quins mètodes; qui educa i a qui s'educa? quins són els agents de l'Educació?; són només els docents?; en quins àmbits s'educa?; només s'educa en l'escola? i els que són els educands són només els alumnes?. Mitjançant aquesta anàlisi interior, he evolucionat fins a crear una imatge del meu ideal docent -amb la certesa que cap mètode, model o teoria és prou bo per a utilitzar-ho de forma exclusiva, hi ha aspectes fonamentals que marquen el meu objectiu: la formació integral de persones lliures com vaig aprendre de Freire, dins d'un àmbit escolar on l'alumnat adquireix el protagonisme que reclamava Freinet, on els donem les eines necessàries perquè adquirisquen l'esperit crític i rebel que transmet Chomsky, i on mai es deixe de lluitar per ajudar a tots, com ens ensenya Pennac. Clar està, des d'un punt de partida ideològic bàsic: formar per al present i el futur, xiquets i xiquetes independents, autònoms, crítics i creatius. No hi ha una opció educadora absolutament vàlida, hem de conjugar aspectes nous $\mathrm{i}$ tradicionals amb els quals em sent còmode $\mathrm{i}$, alhora, incorporar elements pertinents per a la futura labor educativa.

Paraules clau: Innovació; Equip directiu; TIL; Organització escolar; Tasques administratives.

\section{Introducció}

Al marc educatiu actual es constata que l'esperit renovador no ha acabat amb alguns dels mals que continuem arrossegant-se des de l'escola tradicional: massa classes magistrals, massa incomprensió de professors que es desentenen dels seus alumnes i, sobretot, una mancança veritablement significativa de recursos humans i de temps. Es requereix d'una organització escolar acurada, imaginativa i innovadora per tal de suportar la càrrega burocràtica i els entrebancs administratius que fan que la tasca docent estiga constantment influenciada per l'angoixa, per la falta de temps i pels continus canvis educatius que, si fa no fa, la perjudiquen.

Per tant, partint d'aquesta realitat, la necessitat d'atendre a l'organització escolar dels centres adquireix, en la meua opinió, una importància màxima. Organitzar correctament totes les branques que formen part d'una escola i donar resposta al la inestabilitat normativa i als 
canvis en matèria educativa d'una forma innovadora, àgil i respectuosa amb les llibertats $i$ els drets fonamentals, possibilitarà que puguem dur a terme els objectius docents ja mencionats. La didàctica és essencial, com he dit, però si una escola està mal organitzada, de segur que la seua qualitat es veurà reduïda.

III. Objectius

Si l'escola s'organitza com cal i, a més a més, el Projecte Educatiu de Centre fa una aposta per la innovació, estem posant els ciments per aconseguir l'èxit educatiu. D'ací parteix la inquietud per investigar i així trobar respostes als següents interrogants: Com respon un centre escolar a aquests reptes? Quins són el problemes del dia a dia organitzatiu i com influeixen les decisions en la tasca docent? De quina manera influeixen les tasques administratives en la pràctica docent?Els mestres, estem preparats com cal per dur a terme tasques directives? S'hauria de reforçar la preparació universitària en aquest aspecte?

IV. Material i métode

La metodologia que he utilitzat amb l'objectiu d'obtenir respostes a les qüestions plantejades, ha tingut tres vessants: en primer $\| \mathrm{loc}$, l'observació i col-laboració en el treball de l'equip directiu del CEIP Manel Garcia Grau durant més de 5 mesos (Gener-Juny 2014), convertint-me en un membre més de l'equip directiu, assistint a reunions, treballant amb la directora, la cap d'estudis i la secretària, etc. En segon Iloc, mitjançant la preparació d'enquestes dirigides als docents i, per últim, la recopilació de documentació, no tan sols treball en biblioteca o mitjançant Internet, sinó també a través d'entrevistes personals amb docents d'altres escoles o fent ús de l'experiència acumulada a l'any anterior en aquest mateix centre o en els centres de diferents tipologies que varen visitar, dins de l'assignatura de Didàctica i Organització escolar fa dos anys: Unitats Terapèutiques Educatives de centres penitenciaris (UTE), Col-legis Rurals Agrupats (CRA), Escoles Privades, Unitats Pedagògiques Hospitalàries (UPH), etc.

\section{Resultats: respostes als reptes organitzatius}

5.1 Respecte al programa lingüístic: Tractament Integrat de Llengües (TIL).

El programa lingüístic que es du a terme en el centre és el Programa Plurilingüe en I'Itinerari de Immersió Lingüística. En la meua opinió, les dues llengües oficials no estan en equilibri, el castellà va a poc a poc retallant terreny al valencià. L'equip directiu, amb la seua aposta innovadora, va decidir dur a terme una política lingüística per fer front a 
aquesta mancança d'equilibri. Periòdicament, s'organitza un seminari sobre TIL. S'ha fet un treball exhaustiu per preparar al professorat del centre. S'han detectat un seguit de necessitats a l'escola, com ara la duplicitat de continguts (sobretot castellà i valencià), la despesa en llibres per les famílies o el negoci que això suposa a les editorials. Com que el professorat del centre és prou jove $\mathrm{i}$ amb ganes d'innovar, aquesta és l'escola ideal per dur a terme la proposta. En primer lloc, s'ha de planificar l'elaboració de nous materials i, per això, es fa necessari un seminari per assessorar i fer seguiment, i que els docents traguen hores per anar confeccionant materials (reunions de cicle, etc.). Després, s'ha fet una anàlisi dels aspectes principals que envolten la pràctica docent: el currículum i l'angoixa que ens provoca, una anàlisi comparativa dels continguts, la metodologia, etc. A partir d'ací es fa una proposta de treball integrat basada en les tipologies textuals. Per últim, als seminaris es posa en comú el treball setmanal que estan fent els mestres, desenvolupant graelles de continguts de cara al any vinent. Durant la meua estància al CEIP Manel Garcia Grau, vaig participar en alguna d'aquestes reunions i seminaris i vaig ajudar als meus tutors a fer una recerca d'activitats per incorporar-les a la graella d'activitats integrades.

\subsection{Respecte a les noves metodologies didàctiques: projectes de treball i interdisciplinarietat com aposta didàctica del centre.}

Cal reflectir com es relaciona l'Organització Escolar amb la part docent, és a dir , amb la didàctica i la metodologia per la qual aposta el centre. Quan es decideix per una línia metodològica, el centre organitza tota la seua estructura per tal de fer un treball global focalitzat al mètode triat. La metodologia didàctica no és fortuïta sinó que és el resultat d'una acurada reflexió, tenint en compte tots el agents que formen part de la realitat social i educativa del centre.

Treball per projectes i interdisciplinarietat són dos aspectes que, a pesar de tindre un caràcter didàctic, són el millor exemple de com l'estructuració organitzativa del centre a través del PEC s'enfoca per a una millora de la metodologia docent. Qualsevol decisió organitzativa té en compte i aposta per aquests aspectes de cara a millorar els resultats tant acadèmics com formatius integral de l'alumnat.

La interdisciplinarietat és un procés bàsic i essencial en el treball per projectes. Totes les definicions sobre interdisciplinarietat coincideixen en què es treballa una activitat des de tots els punts de vista possibles. La interdisciplinarietat pretén que els xiquets aprenguen de manera globalitzada, sense fraccionar el coneixement que és va adquirint. Una característica important és la seua flexibilitat, ja que permet organitzar els objectius i continguts del currículum segons els interessos i necessitats de l'alumnat. També fonamental, és la cooperació entre docents. Encara que en Infantil també es compleix, és una característica que es veu més reflectida en Primària, ja que encara que es treballe per assignatures, hi ha 
mestres que es coordinen per a treballar un mateix tema per a afavorir el coneixement interdisciplinari.

\subsection{Respecte als desavantatges socials: Contracte-Programa.}

En aquest centre educatiu es porta a terme el que abans era conegut com a Projecte de Compensatòria, però que enguany, es diu Contracteprograma. Està destinat a garantir l'accés, la permanència i la promoció en el sistema educatiu de l'alumnat en situació de desavantatge social, procedent de minories ètniques, de col•lectius d'immigrants, així com de famílies amb greus dificultats socioeconòmiques. De la mateixa manera, amb aquest programa s'atén l'alumnat que ha de romandre llargs períodes d'hospitalització o convalescència. Segons les seues diferents peculiaritats, aquest alumnat presenta, des d'un desfasament escolar significatiu, fins a dificultats d'inserció educativa i necessitats de suport derivades de la seua incorporació tardana a l'escola, d'una escolarització irregular o d'un desconeixement de la llengua vehicular, en procedir d'altres països. Per a dur-lo a terme, es fa necessari dissenyar actuacions que previnguen, compensen i tracten d'eradicar la discriminació de qualsevol tipus, creant un ambient educatiu que fomenta la convivència. Tot açò serà possible si des del centre, tots els que formem la comunitat educativa ens ho proposem. Per tal d'aconseguir-ho, els objectius necessaris són:

\subsection{Respecte a les noves tecnologies: Centre intel-ligent.}

El centre és un dels 18 centres a la Comunitat Valenciana, d'ells 5 a la província de Castelló, que són considerats com a tal. Aquest programa pretén incentivar la introducció de les tecnologies de la informació i comunicació (TIC) en l'Educació i l'intercanvi d'experiències entre el professorat, facilitant així el procés educatiu dels estudiants de la Comunitat Valenciana. L'objectiu del centre educatiu intel•ligent és facilitar l'accés a les tecnologies de la informació i la comunicació des de la totalitat d'espais docents existents en un centre educatiu. Aquest any s'han esmenat gran part dels problemes en aquest aspecte. Les pissarres digitals, després d'un període de letargia, s'han penjat al lloc corresponent. Per altra banda, els problemes que suposa que Lliurex haja de ser l'eina informàtica, provoca que moltes vegades es produeixen problemes a l'hora de traspassar als ordinadors de l'escola tasques que el professorat fa en casa als seus ordinadors personals. En aquest sentit, recentment s'han netejat tots els equips i s'ha tornat a instal•lar la versió més actualitzada de Lliurex.

\subsection{Respecte als canvis legislatius: Procés d'implantació de la LOMQE.}

Al llarg del treball d'investigació, m'he adonat que una de les qüestions que més problemes suposen és el de la inestabilitat legislativa a 
què l'escola espanyola i, en concret, la valenciana, es veu involucrada. Des que es va projectar la LOMQE s'han anat analitzant des de diferents fòrums (govern, sindicats, docents, famílies). Ja no es tracta si la llei és mes o menys profitosa per l'alumnat, els docents etc. -cadascú té la seua opinió. El problema principal, és la precipitació i la falta d'informació.. Tot és extraoficial mentre no siga publicat. Així doncs, l'equip directiu pot anar preparant treball a priori, però no té la seguretat que el que planifica puga complir-se, en funció de si la llei es publica o no. La implantació de la LOMQE m'ha servit per a constatar com la tasca directiva es veu tremendament afectada per la falta de planificació política i legislativa coherent. El procés que s'ha seguit des del centre, sempre amb gran incertesa, és el següent: A través dels mitjans de comunicació i de sindicats xarxes socials etc. arriben les primeres notícies sobre el projecte de llei i les seues diferents anàlisis positives o negatives. Durant tot el període que s'aprova la llei el centre simplement pot anar pensant estratègies per a donar resposta als canvis legals. Però no existeix cap tipus d'assessorament extern.

Per tant, es comença a organitzar en funció de la informació que tingues, o que l'inspector de torn et faça arribar (en el nostre cas, pareix que hi ha sort, i l'inspector ha ajudat prou). La Conselleria no avisa de manera directa al centre dels possibles canvis de la llei, les obligacions que suposaria a l'escola, etc. ni envia informació prèvia als centres. Després d'una primera xarrada amb l'inspector, on s'informa dels canvis, l'equip directiu es reuneix i analitza profundament com afrontar la nova llei, quins canvis suposarà al centre, i quina informació és més important per comentar-la a la resta del claustre. Es van fent els primers passos, mentre la Comunitat Valenciana publica l'esborrany i s'assenten les bases definitives dels aspectes didàctics, currículum, assignatures, etc.

\subsection{Respecte a la jornada continuada: elaboració del projecte d'implantació.}

Davant de la possibilitat que algunes escoles incorporen la jornada continuada al seu centre, va sorgir el plantejament d'aquesta necessitat per part de I'AMPA del centre. La Direcció va acceptar aquest repte organitzatiu que, sense dubte, és el que millor m'ha fet comprendre on pot arribar a treballar l'equip directiu quan està immers en un procés que pot afectar de manera fonamental al futur del centre.

He pogut formar part d'aquesta maquinària organitzativa al llarg de 5 mesos. El procés encara està obert, però el treball ja està fet, i puc assegurar que ha sigut esgotador. 
5.7 Respecte a la necessitat de reciclatge del personal docent: Formació Anual del Professorat (FAP)

La RESOLUCIÓ de 26 d'agost de 2013, de la Direcció General d'Innovació, Ordenació i Política Lingüística, per la qual s'estableix el pla anual de formació permanent del professorat per al curs 2013-2014, recull que la FAP ha de tindre com a objectiu prioritari la millora de la funció docent, tant pel que fa a l'actuació en l'aula com quant a la gestió i la coordinació pedagògica dels centres. Això suposa la consideració del centre docent com el primer nucli de la formació permanent del professorat, capaç de donar resposta a les necessitats sorgides de l'anàlisi de la pràctica docent. D'altra banda, compleix una funció estratègica en la millora de la qualitat de l'educació. El seu correcte desenvolupament requereix oferir diverses modalitats que puguen atendre els aspectes teòrics i pràctics, la formació individual i grupal, la reflexió i l'experimentació. Els grups de treball i els seminaris d'equips docents tenen una característica comuna i diferenciadora, el seu caràcter de formació autònoma, on és el professorat qui realitza el seu propi projecte de formació, d'acord amb les seues necessitats i trajectòria formativa. Per això és necessari regular amb el caràcter més permanent possible el procés pel qual es realitzaran les modalitats de formació autònoma, i precisar com es realitzarà la selecció dels projectes que es presenten, així com el seguiment i avaluació dels mateixos.

\section{ENTREBANCS ORGANITZATIUS I CARREGA BUROCRÀTICA: ESTUDI ESTADÍSTIC.}

L'opinió, per desgràcia generalitzada en la nostra societat, que els mestres treballem poc i que només busquem l'interès personal a l'hora de dur a terme la tasca docent i que ha sigut reforçada per intervencions dels polítics de torn, desprestigiant-nos una vegada darrere l'altra, fa que la tasca docent siga cada vegada més difícil. L'OCDE recull en els seus informes que el professorat a Espanya ensenya una mitjana de cinc hores diàries, enfront de la mitjana de l'OCDE de 4,2 hores. Encara que les dades dels diferents informes PISA són demolidors, la gent no protesta ni exigeix que el percentatge de despesa dedicada a Educació sigui similar al de la mitjana europea, no un dels més baixos de l'OCDE, com és actualment. És més, alguns veuen bé la retallada actual. En el fons, a molta gent li importa ben poc l'Educació dels seus fills, no ho oblidem, l'important és tenir-los aparcats i si aprenen idiomes, anglès sobretot, millor. A més a més, la tasca del tutor ja és prou engoixadora en el que respecta al repartiment i organització del temps, però si hem de combinar tasques burocràtiques de la direcció, caporalia d'estudis o secretaria, l'angoixa es duplica.

Per tant, el meu estudi s'ha dissenyat per s'ha adaptat per acompanyar i ajudar als meus tutors, tant en la tasca docent, com en la administrativa i en la directiva. Durant el meu estudi, he sigut testimoni de moltes de les tasques que du a terme el equip directiu. I no només aquelles 
que recull la llei com a tasques pròpies, sinó també, tot un seguit de reunions, preparacions de projectes, sol-licituds, etc., que han fet que, baix el meu punt de vista, dur a terme el treball del equip directiu d'un centre, havent de compaginar-lo amb la docència tinga un gran mèrit per la implicació, el compromís, la organització, la flexibilitat i el caràcter que es necessita : "Aqueferat, absorbit, molt sovint desbordat, el professorat valencià pateix una sobrecàrrega de treball docent i burocràtic que dificulta l'exercici de la seua tasca pedagògica. La preparació i el desplegament de la tasca docent requereix un repòs, un espai i uns ritmes per a la qual l'exigència reguladora de la Conselleria d'Educació és més un entrebanc que no una ajuda." (STEPV, 2014).

Partint d'aquestes reflexions vaig decidir que seria adient confeccionar una enquesta per a , mitjançant un treball estadístic, descobrir si aquestes sensacions que tenia, podien ser refermades o no, dirigint-lo a un ampli ventall de personal docent de diferents centres escolars.

\section{Objectius de l'enquesta}

Segons un estudi del CEIP Ballester Fandos publicat a la revista Allioli, "cada membre de l'equip directiu d'un centre ha de dur a terme una quantitat de funcions $i$ tasques molt elevada. A la secretària li'n corresponen 73, i a la directora i a la cap d'estudis més de 130. La càrrega burocràtica del equip docent és molt elevada, però també la dels docents sense càrrec directiu". Amb aquesta enquesta, he volgut recopilar dades i informació per tal de constatar l'opinió dels professionals respecte a aquesta conjuntura, la seva problemàtica diària, o el seu nivell d'implicació i preparació per a dur a terme tasques directives.

\section{Univers}

Un total de 278 enquestes emplenades pels docents de més de 10 centres educatius valencians.

\section{Qüestions i resultats}

L'enquesta demana alguns dades personals (edat, especialitat, anys d'experiència, centres on s'ha treballat, si s'ha format part o no de l'equip directiu, càrrecs, etc.). Desprès, s'ha preguntat sobre les hores que es dediquen, tant a tasques docents com a tasques burocràtiques. Hi ha preguntes obertes, com les tasques que es deurien d'eliminar o quines són fonamentals per a la pràctica docent o tancades, com les que fan referencia a la preparació personal. Per últim, vaig deixar espai a la reflexió: 


\section{EXPERIÈNCIA EN EQUIP DIRECTIU (\%)}

NO

- DIRECCIÓ

- CAPORALIA D'ESTUDIS

- SECRETARIA

Gräfic d'elaboració pròtia

\section{6,7}
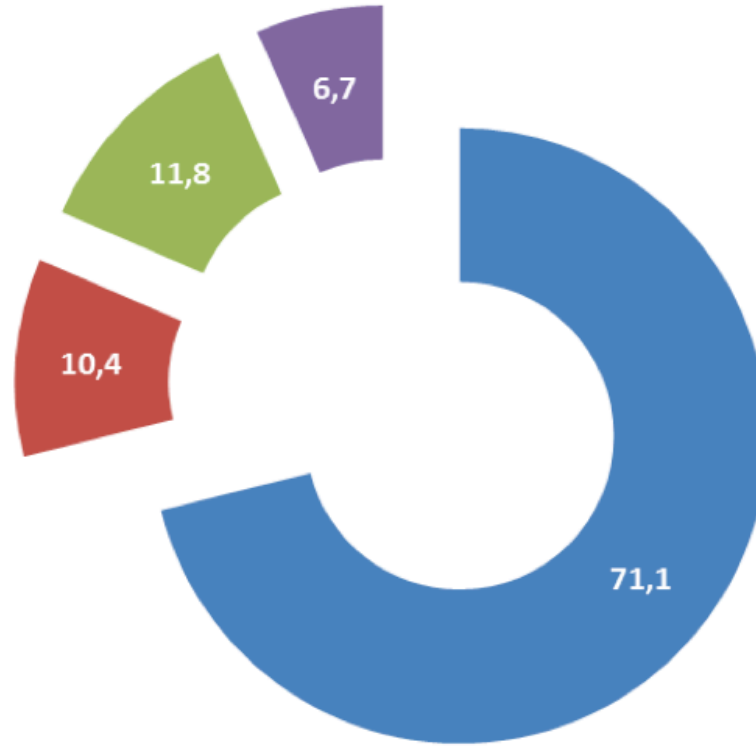

5.En cas afirmatiu, quin càrrec, quants anys, $i$ quants anys feia que exercies com a docent quant ho feres?

Mitjana de 6,5 anys d'experiència.

6.Durant la setmana i dins de la jornada laboral, quantes hores(aprox.) a tasques administratives?

De 0 a 2 hores el 6,1\% dels enquestats; de 3 a 5 hores el 56,3\% dels enquestats $i$ més de 5 hores, el 37,6\% dels enquestats.

7.Durant la setmana i fora de la jornada laboral, quantes hores(aprox.) dediques a tasques administratives?

De 0 a 2 hores el 82,3\% dels enquestats; de 3 a 5 hores el 12,5\% dels enquestats i més de 5 hores, el $5,2 \%$ dels enquestats.

8.Durant la setmana quantes hores tens lliures per dedicar-les a preparar les classes? 
De 0 a 2 hores el 77,6\% dels enquestats; de 3 a 5 hores el 20,1\% dels enquestats $i$ més de 5 hores, el $2,3 \%$ dels enquestats

9.Quantes hores més consideres que et farien falta?

De 0 a 2 hores el 43,5\% dels enquestats; de 3 a 5 hores el 49,2\% dels enquestats $i$ més de 5 hores, el 7,3\% dels enquestat

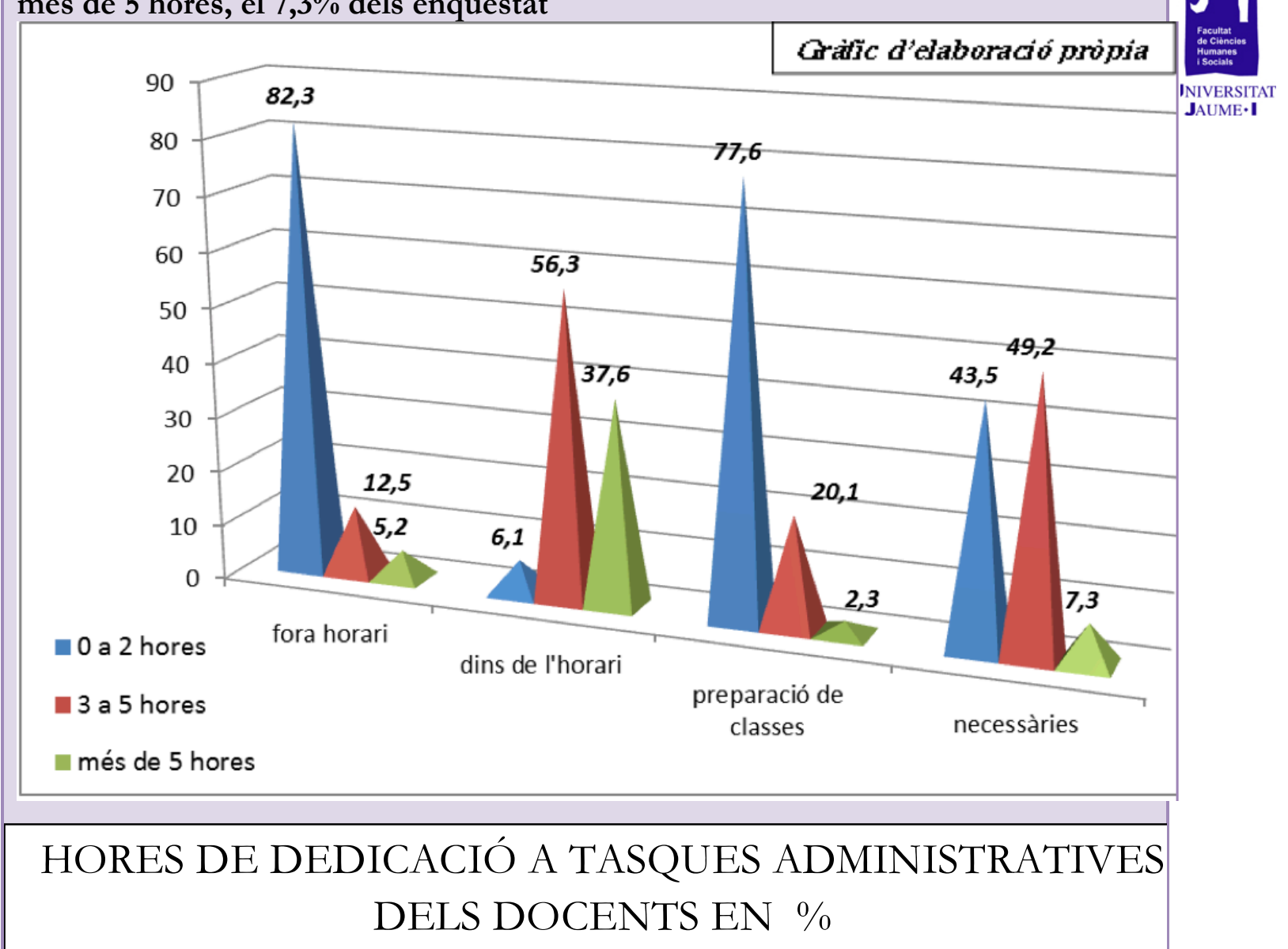

10.De totes les tasques burocràtiques quina /es penses que són suprimible/s o modificable/s?

11.De totes les tasques burocràtiques quina /es penses que són veritablement necessària/es? 
12.CONTESTA D'1 A 10 ( 1: totalment en desacord, 10: totalment d'acord) a les següents preguntes:

Consideres que la preparació universitària és la correcta per assolir càrrecs directius?

\section{NIVELL DE PREPARACIÓ UNIVERSITARIA (\%)}

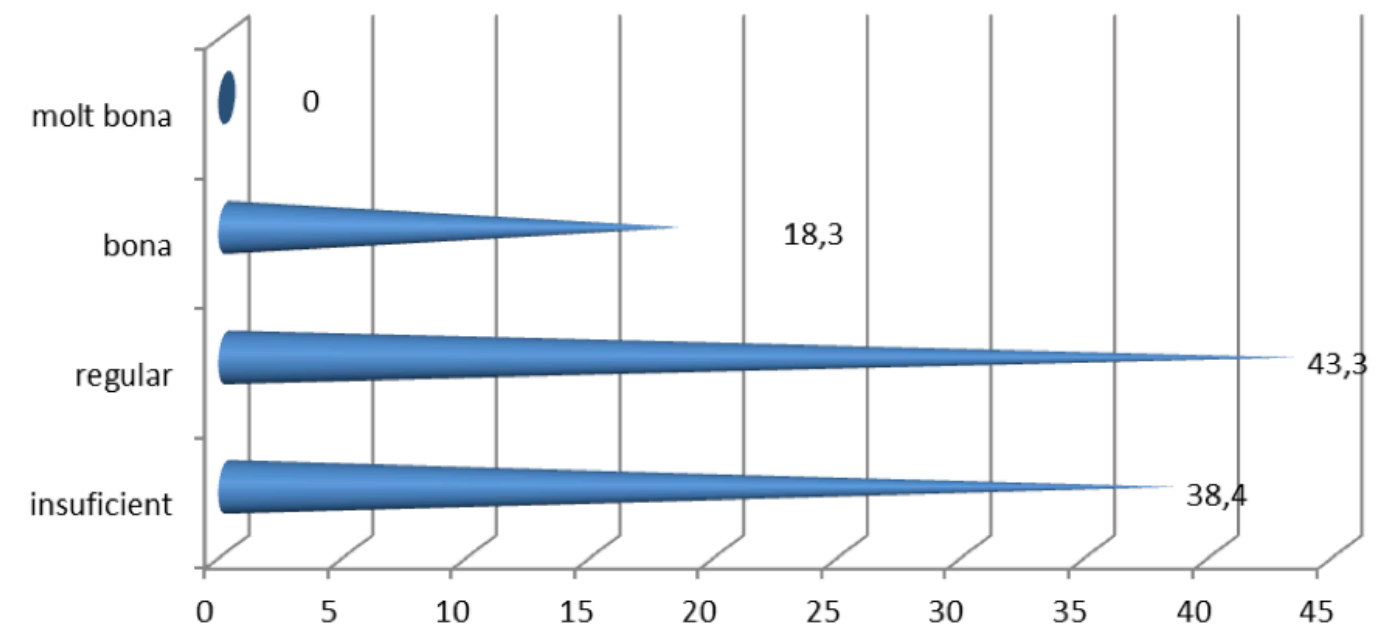

Gräíc d'elaboració projpia

Et veus preparat/da per assolir càrrecs directius amb la teva formació actual? 


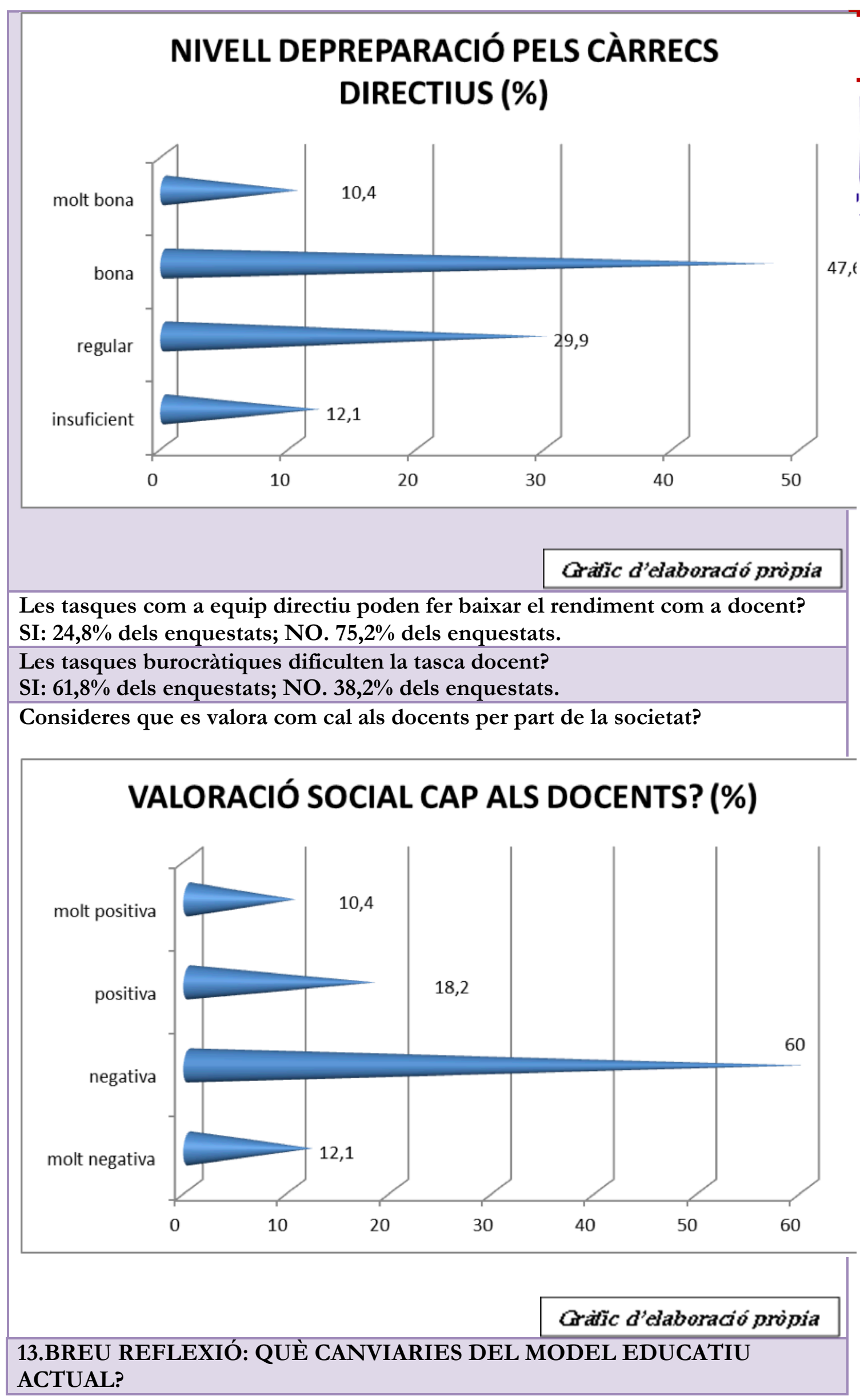

Les tasques com a equip directiu poden fer baixar el rendiment com a docent? SI: $24,8 \%$ dels enquestats; NO. $75,2 \%$ dels enquestats.

Les tasques burocràtiques dificulten la tasca docent?

SI: $61,8 \%$ dels enquestats; NO. $38,2 \%$ dels enquestats.

Consideres que es valora com cal als docents per part de la societat?

\section{VALORACIÓ SOCIAL CAP ALS DOCENTS? (\%)}

Gràtic d'elaboració pròpia 
Després del treball d'investigació he pogut donar resposta a cadascun dels interrogants que em plantejava.

Com respon un centre escolar a aquests reptes?

Una de les conclusions principals de la meua investigació és que l'Organització Escolar ha de ser flexible i oberta als canvis, en continu reciclatge. Ha de buscar la millora dia a dia i aprofitar els recursos d'una manera òptima. Ha d'intentar no barrejar els interessos de les famílies amb les necessitats del centre, ja que l'objectiu és la qualitat educativa docent. L'organització del currículum i la metodologia ha de tindre una línia conjunta de centre perquè es puga innovar per superar la rigidesa generalitzada.

Quins són el problemes del dia a dia organitzatiu i com influeixen les decisions en la tasca docent?

Una queixa important és la referent a l'angoixa que suposa el currículum tancat i l'excessiva càrrega de matèria de les programacions que, normalment, obliga a accelerar les explicacions les últimes setmanes del curs. Són massa llargues i poc productives i, cap al final dels trimestres, es fa insofrible intentar ajustar-les. La majoria dels enquestats coincideixen que hi ha tasca administrativa necessària com la que serveix per a reflexionar sobre la pràctica docent i té com a resultat la seua millora. És també una demanda general la necessitat de conciliar la vida laboral i familiar, tant de famílies, com de docents, reivindicant l'escola com un lloc per educar, i no un lloc on poder deixar els fills tot el dia a mena de guarderia. La mancança de temps, sobretot per a la reflexió docent, és un altre tema recurrent en les reflexions, a l'igual que la necessitat de reduir la ràtio per tal de millorar l'escola i la d'augmentar el personal docent per a fer front a una atenció més individualitzada.

De quina manera influeixen les tasques administratives en la pràctica docent?

Es referma la idea que hi ha excessiva càrrega per al docent. Està comprovat que hi ha un seguit de tasques que són indefugibles, i que beneficien a l'alumnat, com són les relacionades amb el tracte directe amb l'alumne i que tenen una conseqüència positiva en la pràctica docent de I'aula (programacions; avaluacions, etc.). En general hi ha unanimitat quant a la valoració negativa de les tasques consistent en omplir documents, que després és queden oblidats en un calaix o en un arxiu de l'ordinador. Un entrebanc afegit és haver de canalitzar tota la burocràcia a través del programa Itaca, que, moltes vegades funciona malament, i es converteix en un verdader maldecap pels docents o el d'haver de treballar amb Lliurex, que provoca molts handicaps a l'hora de fer activitats informàtiques. La burocràcia ens aboca a la individualitat, els mestres es converteixen en "illes" i es perd la comunicació. Tal vegada siga un instrument per evitar la reflexió.

Els mestres, estem preparats com cal per dur terme tasques directives? 
En general, es considera que el sistema educatiu està carregat de continguts irrellevants i que fa falta un canvi en el sistema tradicional d'ensenyament -aprenentatge, més adaptat als temps actuals. Un canvi de la consciència personal del professorat, augmentant el seu compromís i cultivant $d$ 'intel•ligència emocional, tant de l'alumnat com del mateix professorat. S'ha d'humanitzar l'Educació.

També és notable la demanda d'una perspectiva més crítica del professorat envers les pràctiques d'aula, d'una millor organització dels recursos del centre i de més participació comunitària-des d'una perspectiva inclusiva. L'escola ha de ser un espai on es fomenta la justícia, la participació i la solidaritat., on tots tenen el seu lloc. No caben en ella les desigualtats, ni polítiques educatives que incentiven la classificació i la competitivitat de l'alumnat.

S'hauria de reforçar la preparació universitària en aquest aspecte?

Una gran part del enquestats reconeixen la seua falta de preparació per fer front a les tasques directives i la necessitat d'una millor formació universitària. Actualment, només dediquem una assignatura a aquesta formació i caldria augmentar-la, reduint les hores de docència d'altres menys rellevants.

Per últim, es reconeix la falta de prestigi dels docents i de l'escola com a institució, com a lloc de referència, amb pes moral i educatiu, i la general desídia de tots els agents que forment part de l'Educació per canviar aquesta situació.

L'escola valenciana del futur ha d'abordar els nous reptes amb una postura INNOVADORA, FLEXIBLE I DE QUALITAT i no ha d'esperar que arriben els canvis d'una manera sobtada, ha de promoure'ls, si és en bé de l'alumnat.

\section{Bibliografia}

AntúneZ, S. [et alt]. (1996): “La Organización de Centros. Práctica y fundamentos". Edt. Graó.

Bolívar, A. (2000): "Los centros escolares como organizaciones que aprenden. Promesas y realidades". Edt. La Muralla.

CANTón, I. (1996): "Manual de Organización de centros educativos". Edt.Oikos-Tau.

Carbonell, J. (2002): "La aventura de innovar. El cambio en la escuela". Edt. Morata.

GaIRIN, J.M. [et alt] (2001): “Organización de centros educativos". Edt. Praxis. García, F. (1997): "Organización escolar y gestión de centros educativos”. Edt. Aljibe.

MARTIN, M. (2002): "Planificación de centros educativos: Organización y calidad". Edt. Praxis. 
MAYORdOMO, A. (2002): "La transición a la democracia: Educación y desarrollo político". Revista interuniversitaria, № 21, pp. 19-47.

SÁENZ O. (1992): "Didáctica general. Un enfoque curricular". Edt. Marfil.

VERA, J. M.(2006): “Dirección y gestión de centros docentes. Guía práctica para el trabajo diario del equipo educativo". Edt. Graó.
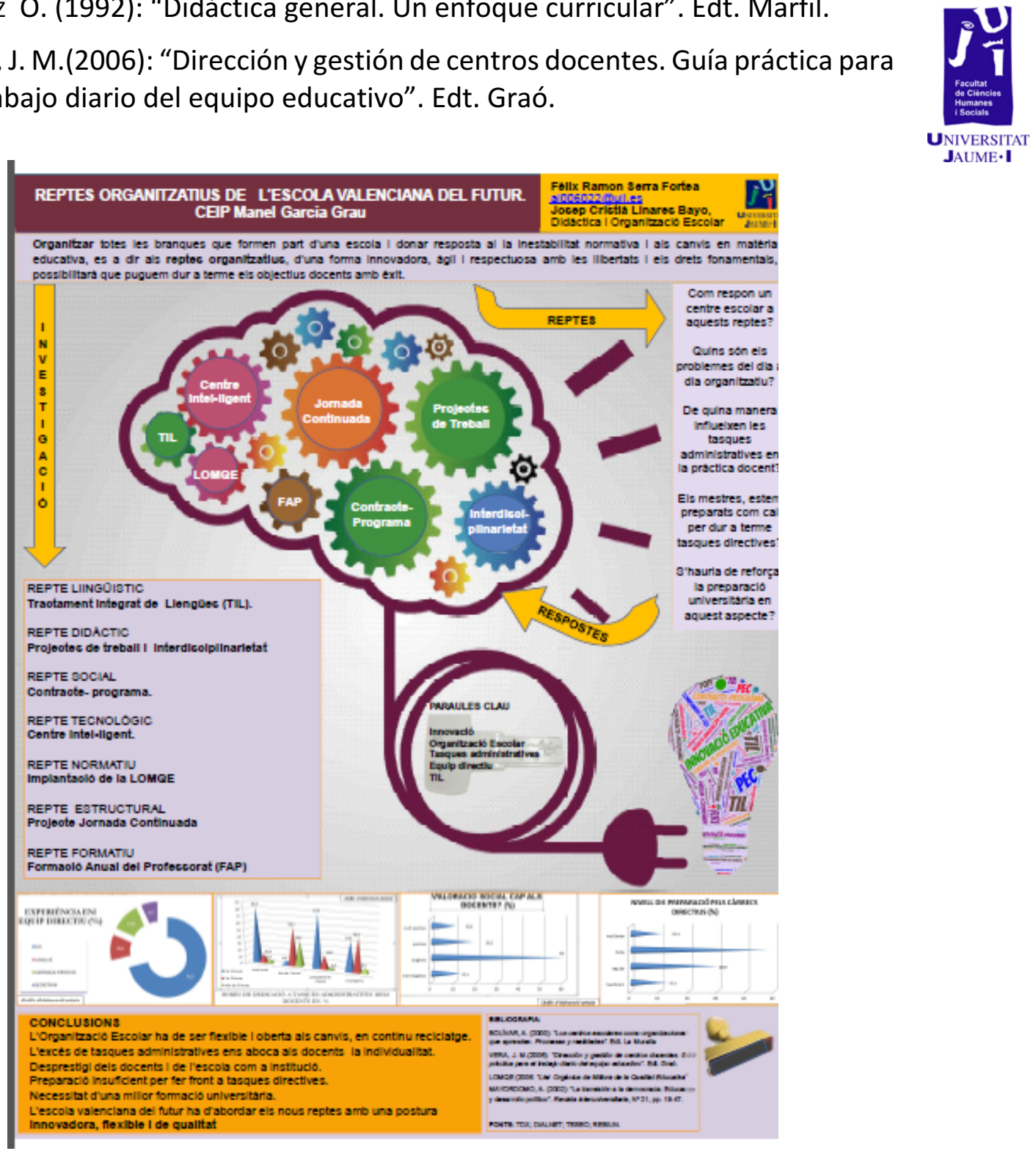